\title{
INDIVIDUALIZAÇÃO DOS CUIDADOS EM SAÚDE E APASSIVAÇÃO DO USUÁRIO NO ÂMBITO DA EDUCAÇÃO EM SAÚDE NA ESTRATÉGIA SAÚDE DA FAMÍLIA
}

\author{
INDIVIDUALIZATION OF HEALTH CARE AND MAKING USERS PASSIVE IN HEALTH EDUCATION IN \\ THE FAMILY HEALTH STRATEGY
}

\section{INDIVIDUALIZACIÓN DE LOS CUIDADOS EN SALUD Y PASIVIDAD DEL USUARIO EN EL ÁMBITO DE LA EDUCACIÓN EN SALUD EN LA ESTRATEGIA SALUD DE LA FAMILIA}

\author{
Gilberto Éder de Oliveira Júnior ${ }^{1}$ \\ Marcel Brentano Diehl ${ }^{2}$ \\ Gerson Mattos ${ }^{3}$ \\ João Luiz Gurgel Calvet da Silveira ${ }^{4}$
}

Resumo A pesquisa que originou este artigo teve como objetivo compreender as representações de profissionais e usuários da Estratégia Saúde da Família sobre educação em saúde. Tratou-se de estudo com abordagem qualitativa e técnicas de observação participante e entrevista, por meio da análise de conteúdo, realizado em 2008 e 2009. A representação do grupo denotou 'educação' e 'saúde' como bens de valor social, cultural e histórico a serem preservados na família e na sociedade em geral, ancorando o cuidado com a saúde em estratégias que se sobrepõem à prescrição de procedimentos e comportamentos. No entanto, profissionais e usuários dos serviços de saúde associam 'educação em saúde' à transmissão de conhecimentos técnicos específicos, a ser realizada por profissionais capacitados. Nas práticas de educação em saúde, prevalecem: prescrição de hábitos saudáveis na dimensão individual; grupos temáticos focados em enfermidades ou estados de saúde específicos; comportamento passivo dos usuários; e dificuldades de adesão e ações de caráter compulsório. A transmissão de conhecimento e a prescrição de hábitos para o autocuidado individual são as formas prevalentes de representar a educação em saúde para todos os sujeitos da pesquisa. As práticas de educação em saúde observadas podem ser caracterizadas como práticas tradicionais de atenção à saúde.

Palavras-chave educação em saúde; saúde coletiva; atenção primária à saúde; representações sociais.
Abstract The study that originated this article aimed to understand the representations of Family Health Strategy professionals and users about education in health. It was an study carried out using a qualitative approach and participant observation and interview techniques through content analysis. It was conducted in 2008 and 2009. The group's representation denoted 'education' and 'health' as assets of social, cultural, and historical value that should be preserved in the family and in society at large, anchoring health care on strategies that overlap the prescription of procedures and behaviors. However, health service professionals and users associate 'health education' to the conveyance of technical knowledge, which should be done by trained professionals. Prevailing in health education practices were prescribing healthy habits in the individual dimension; thematic groups focused on specific diseases or health conditions; the users' passive behavior; difficulties in adherence, and mandatory actions. All study subjects viewed the conveyance of knowledge and the prescribing of habits for individual self-care the prevalent ways of representing health education. Observed health education practices can be characterized as traditional health care practices.

Keywords health education; public health; primary health care; social representations. 


\section{Introdução}

O estudo que deu origem a este artigo teve por objetivo discutir as representações sociais sobre educação em saúde no contexto de práticas desenvolvidas por equipe de profissionais desse setor em unidades da Estratégia Saúde da Família (ESF).

$\mathrm{Na}$ busca por qualificação, o cenário das práticas de saúde no Brasil vem incorporando, de modo rápido e crescente, os discursos acerca da qualidade de vida e das condições que a sustentam em discussões sobre a formação em saúde (Vasconcelos, Frota e Simão, 2006; Brasil, 2007). Nesse contexto, políticas públicas sustentam os propósitos de novos rumos para a saúde coletiva, em que se insere a educação em saúde (Brasil, 2005, 2007).

No cotidiano das conversas informais, expressões criadas e ressignificadas como sinônimos ou princípios de boas práticas em saúde, oriundas de conceitos técnico-científicos ou expressões populares, passam a fazer parte do universo compartilhado por todos (Scliar, 2007). Sistemas de referências socialmente compartilhados norteiam ações e delineiam condutas, mediante saberes comuns que, à primeira vista, apresentam-se difusos e sem potencial de intervenção nas práticas institucionalizadas, alimentando uma unilateralidade pouco representativa do real: aos profissionais compete prescrever; aos usuários, executar. No entanto, são conhecimentos consensuais que têm função 'convencionalizadora' e prescritiva de forma potente e estão presentes, de forma estrutural, antes mesmo de uma racionalidade objetiva do sujeito (Moscovici, 2011).

Essa discussão, ora empreendida, parte do pressuposto de que o conhecimento acerca das representações sociais sobre educação em saúde pode balizar mudanças no cenário vigente. A distância entre o que se diz e o que se faz na educação em saúde precisa ser repensada com base em uma intencionalidade libertadora e não dominadora.

A educação em saúde apresenta-se como parte fundamental da atenção básica no Sistema Único de Saúde (SUS), podendo ser definida como um processo educativo de construção de conhecimentos em saúde que visa à apropriação sobre o tema pela população em geral. É também o conjunto de práticas do setor que contribui para aumentar a autonomia das pessoas no seu cuidado e no debate com os profissionais e os gestores do setor, para alcançar uma atenção em saúde de acordo com suas necessidades. Além disso, potencializa o exercício da participação popular e do controle social sobre as políticas e os serviços de saúde, no sentido de que respondam às necessidades da população. "A educação em saúde deve contribuir para o incentivo à gestão social da saúde" (Brasil, 2005, p. 480).

Essa definição de educação em saúde amplia sua concepção, indicando mudanças nas práticas dos profissionais da saúde, além da imposição de 
hábitos e comportamentos prescritos de forma autoritária e descontextualizada dos valores e necessidades dos sujeitos. Embora também associe a educação em saúde ao conjunto de práticas do setor, tal definição presume a superação da prática tradicional de educação em saúde.

Conforme Vasconcelos, Frota e Simão (2006), a prática tradicional tende a reproduzir uma pedagogia autoritária, comum nas práticas educativas das diferentes categorias profissionais. A superação, proposta em diferentes perspectivas de mudanças, parte do princípio de que o aprendiz, independentemente da função que exerce ou do papel que desempenha, é sujeito ativo do processo de aprendizagem, trazendo para o campo da formação em saúde significados e valores do contexto psicossocial.

Nessa perspectiva e dada a sua complexidade, o conceito de educação em saúde difere, por exemplo, do de promoção da saúde ou formação em saúde. A promoção pode ser resumida no intento de unir esforços individuais, sugerir ações coletivas e político-governamentais e intervir sobre a realidade sanitária e ambiental. Para Garcia e colaboradores (2010), a promoção almeja resolver problemas de saúde da população, visando à melhoria na qualidade de vida.

A educação em saúde está relacionada a uma problemática real e atual, vigente também no campo das instituições, e tem demandado estudos e pesquisas para balizar mudanças no sentido da superação do modelo biomédico em busca de uma proposta mais humanística, de modo a ampliar a compreensão do processo saúde-doença, considerando como relevante o olhar sobre os aspectos subjetivos do adoecimento (Tsuji e Aguilar-da-Silva, 2010; Nogueira, 2009).

A aplicação dos princípios da educação popular no campo da saúde, historicamente marcado pelo conhecimento científico positivista, constitui um desafio considerável. É necessário o reconhecimento de que o saber das classes populares deve ser o ponto de partida do processo de educação em saúde. A concepção referenciada como educação popular em saúde baseia-se nos seguintes princípios: saber ouvir; desmontar a visão mágica; aprender/estar com o outro; assumir a ingenuidade dos educandos; e viver pacientemente impaciente (Brasil, 2007).

No contexto político-institucional, no âmbito do Estado, a educação popular é recomendada como principal metodologia de educação em saúde na Política de Educação Permanente em Saúde e nos pactos apresentados aos municípios, conforme definição do Ministério da Saúde:

A reflexão crítica, o diálogo e a construção compartilhada do conhecimento representam ferramentas que propiciam o encontro entre a cultura popular e a científica (...) convivendo em situações de reciprocidade e cooperação (Brasil, 2005, p. 480). 
Contribui para essa perspectiva a compreensão do princípio da integralidade no campo da saúde, precedida pela integralidade do pensamento e do ensino em saúde, mediante a valorização do diálogo, do acolhimento, da negociação, da interação entre sujeitos, do vínculo e outras possibilidades (González e Almeida, 2010) pouco conhecidas ou valorizadas nos processos tradicionais de educação em saúde. Assim, reorientações nas práticas de educação em saúde exigem revisão do próprio conceito de cuidado, cuja construção se dá na integralidade da atenção no cotidiano dos profissionais de saúde. O propósito de recuperação da dimensão cuidadora está associado à responsabilização dos profissionais pelos resultados das ações de atenção à saúde, ampliando sua capacidade de estabelecer vínculos e dialogar com outras dimensões do processo saúde-doença (Ceccim e Ferla, 2009).

Uma das grandes contribuições das ciências sociais, mais precisamente da antropologia, para a área da saúde foi o pensamento de Lévi-Strauss, que defendeu, por meio de análises estruturalistas, a ideia de que existe semelhança essencial entre o pensamento mítico e o pensamento científico. Os conhecimentos resultam na elaboração de mecanismos de classificação e tecnologias de ação que, por sua vez, advêm das interpretações dos fenômenos reais observados (Lévi-Strauss, 1989).

Contribuição igualmente expressiva para a área da saúde advém da psicologia social, em especial com a teoria das representações sociais (Moscovici, 2011). Desenvolvida no Brasil como desdobramento de uma medicina voltada aos excluídos ou anormais, a psicologia social ocupa-se em compreender condições concretas da existência humana. Pressupõe que, uma vez elucidadas as condições de opressão, exclusão ou ruptura da normalidade, indivíduos e grupos podem ser providos da crítica e ver ampliado o potencial de transformação de si e do outro. O objeto da psicologia social está situado nos processos grupais, como alavanca para a transformação da realidade, em que as representações sociais desempenham um papel fundamental (Jacó-Vilela e Sato, 2012).

Como modalidade específica de conhecimento, as representações sociais são constituídas por informações, imagens, opiniões, crenças ou símbolos e têm por função a elaboração de comportamentos e a comunicação entre indivíduos na vida cotidiana. As representações estão presentes tanto como expressão do universo consensual, que regula a vida cotidiana em dado tempo e lugar, quanto como questões cristalizadas, retificadas pela ciência e preservadas na produção escrita (Moscovici, 2011).

Na dimensão acadêmica, as representações sociais alcançam status teórico e ampliam referenciais para pesquisa, legitimando-se à medida que estabelecem parâmetros cada vez mais claros na explicação de mecanismos que norteiam a ação, definem escolhas e orientam o cotidiano de indivíduos e grupos (Silva, 2009). Podem ser consideradas tanto como técnica de pesquisa quanto como 
abordagem do campo social. São consideradas relevantes, têm aceitação e larga aplicabilidade na área da saúde. A doença ou a saúde, tomadas como fenômenos sociais e entendidas por si e pelas relações que constroem, representam, além de sua configuração biológica, uma realidade construída. Nessa perspectiva, o doente é, antes de tudo, um personagem social (Minayo et al., 2006).

No cenário brasileiro, em especial a partir de 1980, as políticas sociais de integração e promoção da saúde tornam-se elementos indispensáveis à intervenção do Estado, exigindo uma abordagem crítica dos profissionais nos processos de educação em saúde. Na literatura, os tradicionais conceitos geralmente utilizados como verdade científica, tais como preconceito, estereótipo e identidade social, cedem lugar à análise crítica das histórias de vida, das representações sociais, produção de sentido e ideologia (Lima, 2010; Silva e Barros, 2010).

Com base na reflexão apresentada, o estudo que deu origem a este artigo teve por objetivo compreender as representações e práticas de educação em saúde entre usuários da comunidade da Velha Pequena e profissionais da equipe da Estratégia Saúde da Família do município de Blumenau, Santa Catarina, em seis 'grupos garagem' com a média de 14 participantes.

\section{Métodos}

Utilizou-se a abordagem qualitativa com o emprego das técnicas de entrevista não estruturada focalizada (Lakatos e Marconi, 1991) e observação participante (Chizzotti, 2000), realizadas por 12 alunos bolsistas do Programa de Educação pelo Trabalho para a Saúde (PET-Saúde), inseridos em atividades semanais nas unidades de ESF nas comunidades, com supervisão do tutor em reuniões semanais, tendo 'saúde', 'educação' e 'educação em saúde' como expressões indutoras.

As entrevistas foram gravadas em áudio e transcritas na íntegra, submetidas à análise de conteúdo por meio de leituras sucessivas de forma individual e no grupo de pesquisa, de modo a possibilitar a identificação e o grifo de palavras ou expressões mais recorrentes, seguindo-se a sua contagem (enumeração). Nesse processo foram identificadas categorias de análise, como núcleos de significação atribuídos às expressões indutoras relacionadas (Bardin, 2010; Reis e Bellini, 2011).

No estudo aqui apresentado, a teoria das representações sociais constituiu referencial analítico e, com material e métodos próprios, permitiu articular a argumentação sobre as observações registradas e as entrevistas. Ao enfatizar as condições concretas de produção das representações sociais sobre educação em saúde, viabilizou a interlocução com os princípios 
da educação popular e da integralidade, considerados norteadores das políticas de saúde mais recentes e eixos transversais nas diretrizes curriculares de formação em saúde no Brasil (Almeida, 2003; Brasil, 2007).

Dois aspectos foram relevantes na análise. O primeiro dizia respeito à identificação do que era consensual no grupo sobre educação em saúde; o segundo, à contextualização e descrição das práticas de educação em saúde realizadas pelas equipes nas unidades de ESF. A interação entre os dois aspectos permitiu depreender pontos de ancoragem das representações sociais acerca de educação em saúde.

Os sujeitos que participaram da pesquisa, num total de 75, foram definidos com base em suas categorias profissionais, grau de formação e tipo de relação com o serviço: formação superior, contando com cinco enfermeiros, três médicos e um dentista; formação técnica, entre estes os profissionais de enfermagem e de saúde bucal, em número de oito; dez agentes comunitários de saúde; e 48 usuários da unidade de ESF.

O estudo foi financiado com recursos do edital do PET-Saúde n. 24/2011, da Secretaria de Gestão do Trabalho e da Educação da Saúde, do Ministério da Saúde (SGTES-MS). Os participantes foram devidamente esclarecidos sobre o projeto e o caráter voluntário e seus direitos, conforme as normas da resolução n. 196, de 10 de outubro de 1996, do Conselho Nacional de Saúde. O projeto de pesquisa teve a aprovação do Comitê de Ética em Pesquisa em Seres Humanos da Universidade Regional de Blumenau (Furb), conforme o parecer n. 043/2009.

\section{Resultados quantitativos}

A Tabela 1 apresenta as frequências encontradas nos diferentes grupos sobre as representações das categorias de análise: educação, saúde e educação em saúde.

Tabela 1

\begin{tabular}{|c|c|c|c|c|c|c|}
\hline & Sujeitos/Categorias & $\begin{array}{c}\text { Nível } \\
\text { superior }\end{array}$ & Técnicos & $\begin{array}{c}\text { Agentes } \\
\text { comunitários }\end{array}$ & Usuários & Todos \\
\hline \multirow{4}{*}{ Educação } & Conhecimento transmitido & $30 \%$ & $54,5 \%$ & $31 \%$ & $26 \%$ & $30 \%$ \\
\hline & Valor social e histórico & $50 \%$ & $45,5 \%$ & $51 \%$ & $57 \%$ & $54 \%$ \\
\hline & Política pública & $17 \%$ & $0 \%$ & $10 \%$ & $10 \%$ & $10 \%$ \\
\hline & Não define & $3 \%$ & $0 \%$ & $8 \%$ & $7 \%$ & $6 \%$ \\
\hline
\end{tabular}


Continuação - Tabela 1

\begin{tabular}{|c|c|c|c|c|c|c|}
\hline & Sujeitos/Categorias & $\begin{array}{c}\text { Nível } \\
\text { superior }\end{array}$ & Técnicos & $\begin{array}{c}\text { Agentes } \\
\text { comunitários }\end{array}$ & Usuários & Todos \\
\hline & Conceito ampliado & $21 \%$ & $9 \%$ & $19 \%$ & $7 \%$ & $11 \%$ \\
\hline & Autocuidado ampliado & $17 \%$ & $57 \%$ & $31,5 \%$ & $48,5 \%$ & $42,5 \%$ \\
\hline \multirow[t]{4}{*}{ Saúde } & Bem-estar individual & $48 \%$ & $30 \%$ & $37,5 \%$ & $30,5 \%$ & $34 \%$ \\
\hline & Política pública & $14 \%$ & $4 \%$ & $9 \%$ & $9 \%$ & $9 \%$ \\
\hline & Não define & $0 \%$ & $0 \%$ & $3 \%$ & $5 \%$ & $3,5 \%$ \\
\hline & Transmissão/prescrição & $40 \%$ & $33 \%$ & $42 \%$ & $41 \%$ & $40 \%$ \\
\hline Educação & Valor social e histórico & $21 \%$ & $12 \%$ & $12 \%$ & $14 \%$ & $14 \%$ \\
\hline \multirow[t]{3}{*}{ em saúde } & Autocuidado com o corpo & $16 \%$ & $15 \%$ & $18 \%$ & $25 \%$ & $21 \%$ \\
\hline & Política pública & $23 \%$ & $40 \%$ & $28 \%$ & $8 \%$ & $19 \%$ \\
\hline & Não define & $0 \%$ & $0 \%$ & $0 \%$ & $12 \%$ & $6 \%$ \\
\hline
\end{tabular}

Fonte: Os autores.

No conjunto de sujeitos estudados, a educação apareceu de forma prevalente como 'valor social e histórico a ser preservado - cultura, família', valorizando o meio social e familiar, embora houvesse também um reconhecimento do papel de 'transmissão' de conhecimento pelos equipamentos sociais do Estado como a escola. Essa forma de entender a educação, com valorização da cultura e do saber social a ser preservado, se aproxima dos princípios da educação popular (Brasil, 2013).

Sobre a representação do conceito de saúde, percebeu-se com maior frequência o cuidado sobre o corpo, revelando preocupações com higiene, acesso a serviços, funcionalidade, seguindo-se bem-estar individual em oposição a um valor coletivo e social. $\mathrm{O}$ aspecto político da saúde, com base no princípio da cidadania e do papel do Estado, representou a segunda menor frequência entre os usuários e a menor entre os demais grupos.

O conceito ampliado de saúde, conforme a Constituição Brasileira (Fonseca e Corbo, 2007), também foi pouco representado, revelando um desafio a ser superado no processo de politização dos sujeitos para a concretização dos princípios do SUS e da efetivação do controle e da participação social na saúde (Brasil, 2005).

No que se refere à educação em saúde, a categoria 'conhecimento transmitido/prescritivo' foi a mais frequente nos grupos analisados $(40 \%)$, com distribuição semelhante entre os grupos, seguida por 'autocuidado com o corpo' $(21 \%)$, com maior frequência entre os usuários.

Com base na técnica de observação participante, foi possível perceber que as práticas de educação em saúde realizadas apresentavam as seguintes características: objetivos - visavam quase sempre à aquisição de hábitos saudáveis na dimensão individual, preconizados mediante postulados cientificamente 
aceitos; participação da comunidade - o interesse dos usuários em participar dos grupos era frequentemente pequeno, exceto em uma unidade, e geralmente a participação ficava limitada à audiência marcadamente passiva com poucas iniciativas de envolvimento direto no planejamento e na execução da atividade; metodologias e abordagens - em sua maioria, eram formados grupos temáticos focados em enfermidades ou estados de saúde específicos que inspirassem maiores cuidados; motivação - verificaram-se dificuldades na maioria das unidades para a adesão dos sujeitos às atividades educativas, principalmente no formato de grupos que apresentam pouca continuidade; e caráter compulsório - em certas situações, a participação prévia em grupos de educação era condição necessária para a consulta, gerando a obrigatoriedade de participação.

\section{Representações sobre educação em saúde}

A educação em saúde foi representada como 'conhecimento transmitido' de forma mais frequente nos grupos analisados, sendo identificada com as concepções da educação 'bancária' (Freire, 2004), portanto mais distanciadas da educação popular (Brasil, 2007) e dos princípios da integralidade (Xavier e Guimarães, 2004; Silva, 2009) - com uma pequena diferença entre os profissionais de nível técnico, em que essa categoria apareceu em segundo lugar.

O cuidado com o corpo apareceu como a segunda categoria mais recorrente entre os usuários, identificando-se com o conceito de saúde já analisado e revelando a necessidade dos sujeitos em ancorar conceitos mais complexos a outros mais sedimentados.

Como valor social e histórico a ser preservado, a educação em saúde foi pouco representada nos quatro grupos, indicando que o conhecimento popular não é considerado relevante no contexto das práticas de saúde.

Tal forma de representar a educação em saúde revelou, nos grupos investigados, um distanciamento dos princípios da educação popular (Brasil, 2007; Freire, 2004). Esse fato, aliado às necessidades brasileiras mais atuais voltadas à transformação social, implementação de políticas inclusivas e propostas educativas emancipatórias, deverá exigir um esforço de ressignificação na implantação de processos de educação em saúde. As inovações não podem simplesmente mascarar o já existente, mas transformá-lo, o que demanda efetividade nas interações sociais (Mano e Prado, 2010).

Ao comparar as representações de usuários e equipe de saúde, foi possível apresentar indícios de convergência entre educação em saúde e conhecimento transmitido - do mesmo modo, ou talvez com maior intensidade, explicitar divergências entre educação em saúde e as políticas públicas historicamente instaladas como ações de governo e, portanto, vulneráveis, perenes e de pequena influência nas mudanças sociais mais profundas. 
O sentido social de espaço público, igualmente vulnerável e minado pelo direito de propriedade, contribui no reforço da educação como conjunto de procedimentos, na saúde ou fora dela.

A dimensão meramente prescritiva do profissional de saúde pode distanciar os sujeitos, sejam profissionais, sejam usuários envolvidos no processo de educação em saúde. As perspectivas da educação popular em saúde e da integralidade pressupõem a necessária coerência política, de modo a suscitar e fundamentar a mudança, o que está muito além do objetivo de desenvolver hábitos saudáveis no campo individual (Brasil, 2007).

Assim, pode-se compreender que, na saúde, as estratégias curativas ou mesmo preventivas - sejam tomadas de antemão como representação de educação; são elas que estão à frente na maior parte das interações profissional-usuário (ou, mais apropriado ao universo consensual, da relação médico-paciente). Nesse contexto, prevalece dicotômico o 'cuidado do outro', em detrimento da projeção de si no 'cuidado com o outro'.

O Quadro 1 apresenta as expressões indutoras por agrupamentos de sujeitos e seus respectivos núcleos de significação.

Quadro 1

\begin{tabular}{|c|c|c|}
\hline Expressão indutora & Sujeitos & Núcleos de significação \\
\hline Educação & $\begin{array}{l}\text { Enfermeiros, médicos, dentista, } \\
\text { agentes comunitários e usuários }\end{array}$ & $\begin{array}{l}\text { Valor social e histórico a ser preservado } \\
\text { (cultura e família) }\end{array}$ \\
\hline Saúde & $\begin{array}{l}\text { Técnicos de enfermagem e de saúde } \\
\text { bucal e usuários }\end{array}$ & $\begin{array}{l}\text { Cuidado sobre o corpo, higiene, acesso a } \\
\text { serviços e alimentação - capacidade laboral }\end{array}$ \\
\hline Educação em saúde & $\begin{array}{l}\text { Enfermeiros, médicos, dentistas, } \\
\text { agentes comunitários e usuários }\end{array}$ & Conhecimento a ser transmitido - prescrição \\
\hline
\end{tabular}

Fonte: Os autores.

Entre os participantes da pesquisa prevaleceu o consenso de que educação seria, antes de tudo, um bem cultural. Sua preservação dependia da ação das instituições, em especial da escola e, em segundo plano, de políticas públicas como atribuição do Estado. Entre os técnicos de enfermagem e de saúde bucal não prevaleceu a observância quanto ao papel do Estado, situando-se a educação como atribuição primordial da escola.

Sobre o conceito de saúde não houve consenso direto, explicitando vinculação da representação com o espaço social, formação e ocupação profissional dos sujeitos. Para enfermeiros, médicos, dentistas e agentes comunitários, prevaleceu a relevância do bem-estar individual como princípio de saúde. 
Entre os usuários dos serviços de saúde, assim como para técnicos de enfermagem e de saúde bucal, prevaleceram a capacidade laboral, a higiene, os cuidados com a alimentação e o acesso a serviços no combate a doenças como sinônimos de saúde.

O conceito ampliado de saúde apareceu ainda de forma difusa, embora estivesse cada vez mais presente nos espaços formativos, em diretrizes curriculares na educação superior e na legislação e nas políticas de saúde mais recentes. A naturalização de saúde como bem-estar físico, emocional e social era ainda periférica nas referências socialmente construídas, entre os usuários ou por aqueles com a responsabilidade de promovê-la.

Expressões e termos do universo acadêmico foram reproduzidos, de modo consciente e intencional, por acadêmicos e profissionais, e progressivamente passavam a fazer parte do universo consensual. Técnicos e agentes comunitários, ao seu modo, por formação ou influência direta no exercício da função, assimilavam e reproduziam os conceitos formalizados, situando-os com propriedade na condição de saberes experienciais. Os usuários, por sua vez, no intento de se beneficiarem da interação, estabeleciam tacitamente um acordo de apropriação, o que facilitava a comunicação e promovia a efetividade das intervenções.

Para fins de discussão, algumas falas representativas foram transcritas a seguir, apresentando uma codificação que permitiu identificar a categoria profissional ou usuário, a idade, a unidade de origem e o número atribuído ao sujeito da pesquisa.

Saúde para mim está muito ligada à qualidade de vida (enfermeira, 46, ESF WGS, E1).

Saúde é estar bem fisicamente, não ter dor, comer adequadamente, ter lazer, poder praticar um esporte (técnica em enfermagem, 49, ESF WGS, E2).

A saúde é o equilíbrio dos fatores que atacam o organismo e a defesa (dentista, 43, ESF WGS, E3).

Saúde, eu concordo com o conceito que aprendi, é o bem-estar físico, social e mental (técnico em enfermagem, 50, ESF WGS, E4).

Saúde para mim é, além de estar bem fisicamente, sem dor ou impossibilitada por alguma doença, é também estar feliz (usuária, 48, educação básica incompleta, ESF WGS, E5).

Saúde é estar bem consigo mesma, estar bem fisicamente, mentalmente, poder trabalhar e viajar, ter uma vida mais saudável no hábito alimentar, praticar exercícios (usuária, 44, técnica em enfermagem, ESF WGS, E6). 
Assim definidos, os conceitos de educação e de saúde justificaram a representação social identificada no grupo sobre educação em saúde. Ancorada em técnicas de combate à doença, a educação em saúde parece ter como determinante a prescrição de procedimentos proibitivos, que coíbem o mal-estar e as agressões físicas ao organismo, provocando desequilíbrio. Massificadora, a técnica está respaldada no universo reificado pela ciência, tornando-se comum a ponto de prover os próprios usuários do mesmo discurso prescritivo, assimilado e difundido por profissionais da saúde. Estudo semelhante revela que tanto as práticas como as representações dos profissionais de saúde podem revelar resquícios de uma educação bancária, limitada à dimensão preventivista ou excessivamente medicalizadora (Oliveira e Wendhausen, 2014).

No entanto, o provimento fica limitado à superfície. Por um lado, a especificidade dos conteúdos abordados na área da saúde os distancia dos leigos; por outro, a distinção social historicamente construída para as profissões da saúde preserva o distanciamento. Nesse processo, saberes comuns são soterrados para que prevaleçam a ciência e a técnica, e pouco se questiona sobre sua efetividade e intencionalidade.

Entre usuários, a educação se apresentou como cuidado com o corpo. No entanto, essencialmente, e com maior intensidade do que em equipes de saúde, o conteúdo da representação explicitava e agregava valor às interações sociais. Conforme os relatos:

Dizem que saúde é bem-estar, mas bem-estar pessoal não existe se você não se sente forte para realizar a sua função aqui [no espaço social] (usuário, 34, educação básica incompleta, ESF AB, E4) [grifo nosso].

Saber praticar [com o outro], este é o primeiro passo para saber o que é educação. É assim, na prática, com a educação em saúde (usuária, 62, educação básica incompleta, ESF AB, E6) [grifo nosso].

Saúde é ter vontade de viver, é trabalhar sempre, nunca se aposentar, pensar positivo, (...) é preciso buscar Deus, a família e os outros para se ter forças. Educação em saúde é isso, treinar sempre a vontade de viver (usuária, 58, educação básica incompleta, ESF AB, E8) [grifo nosso].

\section{Conclusões}

Mediante tais circunstâncias, foi possível refletir sobre possibilidades emergentes no cenário da saúde, antevendo-as em condições, talvez, de contribuir para o rompimento do paradigma hegemônico e tradicional voltado à 
medicalização e prescrição unilateral de hábitos na ação dos profissionais. Se, por um lado, o tratamento das doenças prescinde de saberes específicos e a ciência nisso muito contribui, por outro a interação entre os sujeitos, o conhecimento e a assunção de seus saberes podem sinalizar rumos diferentes para o trabalho em saúde. Pelo que se apresentou neste estudo, há menos resistência por parte de usuários em encontrar alternativas para as rotinas de saúde 'com-o-outro' e 'como-o-outro' do que se possa pressupor.

Dessa forma, a educação em saúde, orientada pelos princípios da educação popular e da integralidade, deve ir além do saber e fazer técnicos (Silveira, 2008). Ao considerar a realidade social e o contexto político dos sujeitos como potencial para imprimir as mudanças necessárias no contexto social, alcança, por decorrência, melhorias do cuidado e da saúde.

A ressignificação dos conceitos, objetivos e princípios envolvidos em processos de educação em saúde precisa considerar os diferentes sujeitos sociais desse processo, na promoção de ações voltadas à educação permanente, ao controle social das doenças, à promoção da saúde e do espaço social. Nesse sentido, o reconhecimento, a mobilização e a incorporação de movimentos sociais em políticas de saúde desempenham um papel preponderante na evolução dos princípios educativos.

A transmissão de conhecimentos técnicos e a prescrição de hábitos para o autocuidado individual foram aspectos prevalentes nas representações de educação em saúde entre os sujeitos da pesquisa aqui apresentada, sejam eles profissionais, sejam usuários da ESF. Assim, as representações identificadas no grupo tiveram como nuclear a orientação para práticas tradicionais de atenção à saúde, com destaque para o tratamento ou prevenção de doenças, e apresentaram como periféricos aspectos relativos à educação em saúde e à sua dinâmica.

A capacitação mediante novas metodologias educativas foi uma demanda verbalizada por alguns profissionais, a qual poderia sinalizar indícios de mudança no cenário da educação em saúde, no sentido de uma educação libertadora ou, em sentido oposto, um reforço do quadro vigente, limitado à aquisição de técnicas para o tratamento de doenças.

\section{Colaboradores}

Gilberto Éder de Oliveira Júnior e Marcel Brentano Diehl fizeram a revisão de literatura, coleta de dados, transcrição e análise de dados e redação do artigo. Gerson Mattos participou da discussão dos dados, revisão de con- 
teúdo e redação do artigo. João Luiz Gurgel Calvet da Silveira foi o responsável pela orientação e supervisão, redação e revisão de conteúdo do artigo. Não há conflitos de interesse entre os autores.

Resumen La investigación que originó este artículo tuvo como objetivo comprender las representaciones de profesionales y usuarios de la Estrategia Salud de la Familia sobre educación en salud. Se trató de un estudio con enfoque cualitativo y técnicas de observación participante y entrevista, por medio del análisis de contenido, realizado en 2008 y 2009. La representación del grupo denotó "educación" y "salud" como bienes de valor social, cultural e histórico a ser preservados en la familia y en la sociedad en general, anclando el cuidado con la salud en estrategias que se sobreponen a la prescripción de procedimientos y comportamientos. Sin embargo, profesionales y usuarios de los servicios de salud asocian "educación en salud" a la transmisión de conocimientos técnicos específicos, a ser realizada por profesionales capacitados. En las prácticas de educación en salud, prevalecen: prescripción de hábitos saludables en la dimensión individual; grupos temáticos centrados en enfermedades o estados de salud específicos; comportamiento pasivo de los usuarios; y dificultades de adhesión y acciones de carácter compulsorio. La transmisión de conocimiento y la prescripción de hábitos para el autocuidado individual son las formas prevalentes de representar la educación en salud para todos los participantes de la investigación. Las prácticas de educación en salud observadas pueden caracterizarse como prácticas tradicionales de atención de la salud.

Palabras clave educación en salud; salud colectiva; atención primaria de la salud; representaciones sociales.

\section{Notas}

1 Universidade Regional de Blumenau, Departamento de Medicina, Blumenau, Santa Catarina, Brasil.

<geoliveirajr22@gmail.com>

Correspondência: Rua Iguaçu, 404, CEP 89030-030, Itoupava Seca, Blumenau, Santa Catarina, Brasil.

2 Universidade Regional de Blumenau, Departamento de Medicina, Blumenau, Santa Catarina, Brasil.

$<$ marceldiehl@gmail.com>

3 Universidade Regional de Blumenau, Programa de Pós-Graduação em Saúde Coletiva, Blumenau, Santa Catarina, Brasil.

<germattos@furb.br>

4 Universidade Regional de Blumenau, Departamento de Odontologia, Programa de Pós-Graduação em Saúde Coletiva, Blumenau, Santa Catarina, Brasil.

<gurgeljl@gmail.com> 


\section{Referências}

ALMEIDA, Márcio. Diretrizes curriculares nacionais para os cursos universitários da área da saúde. Londrina: Rede Unida, 2003.

BARDIN, Laurence. Análise de conteúdo. 4. ed. Lisboa: Edições 70, 2010.

BRASIL. Ministério da Saúde. Conselho Nacional de Secretários Municipais de Saúde. O SUS de A a Z: garantindo saúde nos municípios. Brasília: Ministério da Saúde, 2005. Disponível em: <http://dms.ufpel.edu.br/ ares/bitstream/handle/123456789/25/sus_ 3edicao_completo.pdf?sequence $=1>$. Acesso em: 15 dez. 2016.

BRASIL. Ministério da Saúde. Secretaria de Gestão Estratégica e Participativa. Departamento de Apoio à Gestão Participativa. $\mathrm{Ca}$ derno de educação popular e saúde. Brasília: Ministério da Saúde, 2007. Disponível em: <http://redepopsaude.com.br/wp-content/ uploads/2016/03/Caderno-EPS.pdf $>$. Acesso em: 12 dez. 2016.

BRASIL. Conselho Nacional de Secretários de Saúde. Política Nacional de Educação Popular em Saúde. Nota técnica n. 16/2013. Disponível em: <www.crpsp.org.br/diverpsi/ arquivos/PNEPS-2012.PDF $>$. Acesso em: 15 dez. 2016.

CECCIM, Ricardo B.; FERLA, Alcindo A. Educação e saúde: ensino e cidadania como travessia de fronteiras. Trabalho, Educação e Saúde, Rio de Janeiro, v. 6, n. 3, p. 443-456, nov. 2008-fev. 2009.

CHIzZOTTI, Antônio. Pesquisa em ciências humanas e sociais. 4. ed. São Paulo: Cortez, 2000.

FONSECA, Angélica F.; CORBO, Ana M. A. (orgs.). O território e o processo saúde-doença. Rio de Janeiro: EPSJV, 2007.

FREIRE, Paulo. Pedagogia do oprimido. 21. ed. Rio de Janeiro: Paz e Terra, 2004.
GARCIA, Adir V. et al. Concepções de promoção da saúde que permeiam o ideário de equipes da Estratégia Saúde da Família da Grande Florianópolis. Revista de Saúde Pública de Santa Catarina, Florianópolis, v. 3, n. 1, p. 42-56, jan.-jun. 2010.

GONZÁLEZ, Alberto D.; ALMEIDA, Márcio J. Integralidade da saúde: norteando mudanças na graduação dos novos profissionais. Ciência \& Saúde Coletiva, Rio de Janeiro, v. 15, n. 3, p. 757-762, 2010.

JACÓ-VILELA, Ana M; SATO, Leni (orgs.). Diálogos em psicologia social [on-line]. Rio de Janeiro: Centro Edelstein de Pesquisas Sociais, 2012. Disponível em: <http://static. scielo.org/scielobooks/vfgfh/pdf/jaco9788579820601.pdf>. Acesso em: 15 dez. 2016.

LAKATOS, Eva M.; MARCONI, Marina A. Fundamentos de metodologia científica. 3. ed. São Paulo: Atlas, 1991.

LÉVI-STRAUSS, Claude. Mito e significado. Lisboa: Edições 70, 1989. (Perspectivas do homem, 8). Tradução de 'Myth and meaning'.

LIMA, Aluísio F. Gênese, desenvolvimento e redefinição da psicologia social: da separação epistemológica ao compromisso com a práxis. Revista Psicologia e Saúde, Campo Grande, v. 2, n. 1, p. 72-90, 2010.

MANO, Maria A. M.; PRADO, Ernande V. Vivências de educação popular na atenção primária à saúde: a realidade e a utopia. São Carlos, SP: EdUFSCar, 2010.

MINAYO, Maria C. S. et al. Tratado de saúde coletiva. São Paulo: Hucitec, 2006.

MOSCOVICI, Serge. Representações sociais: investigações em psicologia social. 8. ed. Petrópolis, RJ: Vozes, 2011.

NOGUEIRA, Maria I. As mudanças na educação médica brasileira em perspectiva: reflexões 
sobre a emergência de um novo estilo de pensamento. Revista Brasileira de Educação Médica, Niterói, RJ, v. 33, n. 2, p. 262-270, 2009.

OLIVEIRA, Silvia R. G.; WENDHAUSEN, Águeda L. P. (Re)significando a educação em saúde: dificuldades e possibilidades da Estratégia Saúde da Família. Trabalho, Educação e Saúde, Rio de Janeiro, v. 12, n. 1, p. 129-147, 2014.

REIS, Sebastiana L. A.; BELLINI, Luiza M. Representações sociais: teoria, procedimentos metodológicos e educação ambiental. Acta Scientiarum. Human and Social Sciences, Maringá, PR, v. 33, n. 2, p. 149-159, 2011.

SCLIAR, Moacyr J. História do conceito de saúde. Physis: Revista de Saúde Coletiva, Rio de Janeiro, v. 17, n. 1, p. 29-41, 2007.

SILVA, Neide M. A. Cada curicaca em seu nicho: o pertencimento à linha de pesquisa. In: SILVA, Neide M. A. (org.). Representações sociais em educação: determinantes teóricos e pesquisa. Blumenau, SC: Edifurb, 2009.
SILVA, Valdir P; BARROS, Denise D. Método história oral de vida: contribuições para a pesquisa qualitativa em terapia ocupacional. Revista de Terapia Ocupacional da Universidade de São Paulo, São Paulo, v. 21, n. 1, p. 68-73, jan.-abr. 2010.

SILVEIRA, João L. G. C. (org.). Liga de saúde coletiva: extensão popular em busca da integralidade. Blumenau, SC: Edifurb, 2008.

TSUJI, Hissachi; AGUILAR-DA-SILVA, Rinaldo H. Aprender e ensinar na escola vestida de branco. São Paulo: Phorte, 2010.

VASCONCELOS, Eymard M.; FROTA, Lia H.; SIMON, Eduardo. Perplexidade na universidade: vivências nos cursos de saúde. São Paulo: Hucitec, 2006.

XAVIER, Caco; GUIMARÃES, Cátia. Uma semiótica da integralidade: o signo da integralidade e o papel da comunicação. In: PINHEIRO, Roseni; MATTOS, Ruben A. Cuidado: as fronteiras da integralidade. Rio de Janeiro: Hucitec, 2004. p. 133-155.

Recebido em 25/06/2013

Aprovado em 17/11/2016 